\title{
PERISTALTIC FLOW OF BLOOD THROUGH COAXIAL VERTICAL CHANNELWITH EFFECT OF MAGNETIC FIELD: BLOOD FLOW STUDY
}

\author{
S.Ravi Kumar \\ Department of Mathematics, NBKR Institute of Science and Technology, \\ Vidyanagar, SPSR Nellore, Andhra Pradesh, India.Pin-524413.
}

\begin{abstract}
The present paper investigates the effects of peristaltic flow of blood through coaxial vertical channel with effect of magnetic field: blood flow study.The effects of various physical parameters on axial velocity and pressure gradient have been computed numerically. It is observed that the maximum velocity increases with increase in Magnetic field (M) even though for phase shipt $\square \square \square \square \square / 4$ for all the two cases $\frac{d p}{d x}=-0.5$, $\frac{d p}{d x}=-1$. However, opposite effects are noticed for $\frac{d p}{d x}=0.5, \frac{d p}{d x}=1$.
\end{abstract}

KEYWORDS: Peristaltic fluid flow, Reynolds number, MHDand coaxial vertical channel.

\section{INTRODUCTION}

Peristalsis is now well known to physiologists to be one of the major mechanisms for fluid transport in many biological systems. In the living systems peristalsis is the mechanism to propel foodstuffs through esophagus and the vasomotion of small blood vessels. Engineers developed pumps having industrial and physiological applications adapting the principle of peristalsis.Also, finger and roller pumps are frequently used for pumping corrosive or very pure materials so as to prevent direct contact of the fluid with the pump's internal surfaces. The problem of the mechanism of peristaltic transport has attracted the attention of many investigators since the first investigation of Latham [1].The fundamental studies on peristalsis were performed by Fung and Yih [2] using laboratory frame of reference and then by Shapiro et al. [3] using wave frame of reference. A number of analytical, numerical and experimental studies of peristaltic flows of different fluids have been reported by $[4,5,6,7,8,9,10,11,12,13$ and 14]The peristaltic fluid flow through channels with flexible walls has been studied by Ravi Kumar et al [15-22].

Peristalsis is an important physiological mechanism for mixing and transporting fluids, which is generated by a progressive wave of area contraction or expansion moving on the wall of the tube containing fluid. The peristaltic fluid flows involving Newtonian and non-Newtonian fluids have been studied by[23-34].The Magneto hydrodynamic (MHD) flow of a fluid in a channel with peristalsis is of interest in connection with certain flow problems of the movement of conductive physiological fluids e.g. the blood and blood pump machines, and with the need for theoretical research on the operation of a peristaltic MHD Compressor. Blood is regarded as a suspension of small cells in plasma. Moreover, it is known that in blood flows in two layers, arteries, a core layerand the plasma layer near the wall consisting of suspension of cells in the plasma. The red blood cells, which contain iron, are magnetic in nature, the core may be treated as magnetic field.Abd El Hakeem et al [35] has been studied byEffects of a magnetic field on trapping 
through peristaltic motion for generalize Newtonian fluid in a channel. Non-liner peristaltic flow of a non- Newtonian fluid has been studied by [36, 37].Recently, the study of magnetohydrodynamic (MHD) flow of electrically conducting fluids on peristaltic motion has become a subject of growing interest for researchers and clinicians. This is due to the fact that such studies are useful particularly for pumping of blood and magnetic resonance imaging. Theoretical work of Agarwal and Anwaruddin[38] explored the effect of magnetic field on the flow of blood in atherosclerotic vessels of blood pump during cardiac operations. Li et al. [39] observed that an impulsive magnetic field can be used for a therapeutic treatment of patients who have stone fragments in their urinary tract. AmitMedhavi[40] studied Peristaltic Pumping of a NonNewtonian Fluid.AmitMedhavi and U. K. Singh [41] studied Peristaltic Induced Flow of a Particulate Suspension in a Non-Uniform Geometry.

\section{MATHEMATICAL FORMULATION AND SOLUTION OF THE PROBLEM}

Consider the Peristaltic flow of blood through coaxial vertical channel with effect of magnetic field: blood flow study. We assume that a uniform magnetic field strength $\mathrm{B}_{0}$ is applied in the transverse direction to the direction of the flow (i.e., along the direction of the y-axis) and the induced magnetic field is assumed to be negligible.

The equations of the channel walls is given by

$$
\begin{aligned}
& Y=h_{1}{ }^{*}\left(X^{*}, t^{*}\right)=d_{1}+a_{1} \cos \frac{2 \pi}{\lambda}\left(X^{*}-c t^{*}\right) \\
& Y=h_{2}{ }^{*}\left(X^{*}, t^{*}\right)=-d_{2}-a_{2} \cos \frac{2 \pi}{\lambda}\left(\left(X^{*}-c t^{*}\right)+\theta\right)
\end{aligned}
$$

Where $a_{1}, a_{2}$ amplitudes of the waves, $\mathrm{d}_{1}+\mathrm{d}_{2}$ areis the width of the channel $\lambda$ is the wave length, $\theta$ is the phase differences $(0 \leq \theta \leq \pi)$, $\mathrm{c}$ is the propagation velocity and $\mathrm{t}$ is the time.

We introduce laboratory frame $\left(x^{*}, y^{*}\right)$ and the laboratory frame $\left(x^{*}, y^{*}\right)$ flow is unsteady. The coordinates and velocities in the wave and lab frames related through the following expressions are

$$
x^{*}=X^{*}-c t^{*}, y^{*}=Y^{*}, u^{*}\left(x^{*}, y^{*}\right)=U^{*}-c, v^{*}\left(x^{*}, y^{*}\right)=V^{*} \text { and } p^{*}\left(x^{*}\right)=P^{*}\left(X^{*}, t^{*}\right)
$$

Where, $\left(u^{*}, v^{*}\right)$ and $\left(U^{*}, V^{*}\right)$ are the velocity components in the wave frame.

The equations governing wave frame of the present problem are given by

$$
\begin{aligned}
& u^{*}{ }_{x}+v^{*}{ }_{y}=0 \\
& u^{*}{ }_{t}+u^{*} u^{*}{ }_{x}+v^{*} u_{y}=-\frac{1}{\rho} \frac{\partial \mathrm{p}}{\partial \mathrm{x}}+\frac{\mu}{\rho}\left\lfloor u^{*}{ }_{x x}+u^{*}{ }_{y y}\right\rfloor-\frac{\sigma}{\rho}\left[\mathrm{B}_{0}{ }^{2}\right]\left[u^{*}+c\right] \\
& v^{*}{ }_{t}+u v_{x}+v^{*} v^{*}{ }_{y}=-\frac{1}{\rho} \frac{\partial \mathrm{p}}{\partial \mathrm{x}}+\frac{\mu}{\rho}\left\lfloor v^{*}{ }_{x x}+v^{*}{ }_{y y}\right\rfloor-\frac{\sigma}{\rho}\left[\mathrm{B}_{0}{ }^{2}\right]\left[v^{*}+c\right]
\end{aligned}
$$

$\rho$ is the density of the fluid, $\mu$ is the coefficient of the viscosity, $\sigma$ is the electrical conductivity of the fluid and $\mathrm{B}_{0}$ is the constant transverse magnetic field.

We introduce the following dimensionless parameters:

$$
\mathrm{x}=\frac{\mathrm{x}^{*}}{\lambda} \mathrm{y}=\frac{\mathrm{y}^{*}}{\mathrm{~d}_{1}} \mathrm{u}=\frac{\mathrm{u}^{*}}{\mathrm{c}} \mathrm{v}=\frac{\lambda \mathrm{v}^{*}}{\mathrm{~d}_{1} \mathrm{c}} \quad \mathrm{P}=\frac{\mathrm{d}_{1}{ }^{2} \mathrm{p}^{*}}{\lambda \mu \mathrm{c}} \quad \mathrm{t}=\frac{\mathrm{ct}^{*}}{\lambda}, d=\frac{\mathrm{d}_{2}}{\mathrm{~d}_{1}}
$$


International Journal of Recent advances in Mechanical Engineering (IJMECH) Vol.3, No.4, November 2014

$$
\begin{gathered}
\mathrm{Re}=\frac{\rho c \mathrm{~d}_{1}}{\mu}, \mathrm{M}=\sqrt{\frac{\sigma}{\mu}} \mathrm{B}_{0} \mathrm{~d}_{1}, \delta=\frac{\mathrm{a}_{0}}{\lambda}, \mathrm{h}_{1}=1+\phi_{1} \cos 2 \pi \mathrm{x} \\
\mathrm{h}_{2}=-\mathrm{d}-\Phi_{2} \cos (2 \pi \mathrm{x}+\theta), \Phi_{1}=\frac{\mathrm{a}_{1}}{\mathrm{~d}_{1}}, \Phi_{2}=\frac{\mathrm{a}_{2}}{\mathrm{~d}_{1}}
\end{gathered}
$$

Where, $\mathrm{Re}$ is the Reynolds number, $\mathrm{P}$ is the pressure and $\mathrm{M}$ is the Hartmann number respectively. The governing equations in dimensionless form can be written as

$u_{x}+v_{y}=0$

$\operatorname{Re} \delta\left[\mathrm{u}_{\mathrm{t}}+\mathrm{u} \mathrm{u}_{\mathrm{x}}+\mathrm{vu}_{\mathrm{y}}\right]=\left[-\frac{\partial \mathrm{p}}{\partial \mathrm{x}}+\delta^{2} \mathrm{u}_{\mathrm{xx}}+\mathrm{u}_{\mathrm{yy}}-\left(\mathrm{M}^{2}\right) \mathrm{u}-\mathrm{M}^{2}\right]$

$\operatorname{Re} \delta^{3}\left[\mathrm{v}_{\mathrm{t}}+\mathrm{u} \mathrm{v}_{\mathrm{x}}+\mathrm{vv}_{\mathrm{y}}\right]=\left[-\frac{\partial \mathrm{p}}{\partial \mathrm{y}}+\delta^{4} \mathrm{v}_{\mathrm{xx}}+\delta^{2} \mathrm{v}_{\mathrm{yy}}-\mathrm{M}^{2} \delta^{2} \mathrm{v}\right]$

Using long wavelength (i.e., $\delta<<1$ ) and negligible inertia (i.e., $R e \rightarrow 0$ ) approximations, wehave

$\frac{\partial p}{\partial y}=0$

$$
\frac{\partial^{2} \mathrm{u}}{\partial \mathrm{y}^{2}}-\left(\mathrm{M}^{2}\right) \mathrm{u}-\mathrm{M}^{2}=-\frac{\partial \mathrm{p}}{\partial \mathrm{x}}(9)
$$

In the wave frame the boundary conditions are

$$
\begin{aligned}
& \mathrm{u}=-1 \text { aty }=h_{1}, \quad \mathrm{u}=-1 \quad \text { at } \mathrm{y}=h_{2} \\
& \frac{\partial^{2} u}{\partial y^{2}}=0 \text { at } \mathrm{y}=h_{1}, \frac{\partial^{2} u}{\partial y^{2}}=0 \text { at } \mathrm{y}=h_{2}
\end{aligned}
$$

Solving equation (13) using the boundary conditions (15 and 16), we get

$$
\begin{aligned}
& u=[A-1] N_{1} \operatorname{Sinh}\left[\alpha_{1} y\right]+[A-1] N_{2} \operatorname{Cosh}\left[\alpha_{1} y\right]-A \\
& \text { Where } \alpha_{1}=\sqrt{\mathrm{M}^{2}}, N_{1}=\frac{\left[\operatorname{Cosh}\left[\alpha_{1} h_{2}\right]-\operatorname{Cosh}\left[\alpha_{1} h_{1}\right]\right]}{\left[\operatorname{Sinh}\left[\alpha_{1} h_{1}\right] \operatorname{Cosh}\left[\alpha_{1} h_{2}\right]-\operatorname{Sinh}\left[\alpha_{1} h_{2}\right] \operatorname{Cosh}\left[\alpha_{1} h_{1}\right]\right]} \\
& \qquad N_{2}=\frac{\left[\operatorname{Sinh}\left[\alpha_{1} h_{1}\right]-\operatorname{Sinh}\left[\alpha_{1} h_{2}\right]\right]}{\left[\operatorname{Sinh}\left[\alpha_{1} h_{1}\right] \operatorname{Cosh}\left[\alpha_{1} h_{2}\right]-\operatorname{Sinh}\left[\alpha_{1} h_{2}\right] \operatorname{Cosh}\left[\alpha_{1} h_{1}\right]\right]}, A=\left[1+\frac{\frac{d p}{d x}}{B}\right]
\end{aligned}
$$

The rate of volume flow $\mathrm{q}$ is given as

$$
\begin{gathered}
q=\int_{h_{1}(x)}^{h_{2}(x)} u d y= \\
\qquad A-1]\left[\frac{N_{1}}{\alpha_{1}}\left[\left[\operatorname{Cosh}\left[\alpha_{1} h_{2}\right]-\operatorname{Cosh}\left[\alpha_{1} h_{1}\right]\right]\right]\right]+[A-1]\left[\frac{N_{2}}{\alpha_{1}}\left[\left[\operatorname{Sinh}\left[\alpha_{1} h_{2}\right]-\operatorname{Sinh}\left[\alpha_{1} h_{1}\right]\right]\right]\right]- \\
\left.h_{1}\right]\left[h_{2}-\right.
\end{gathered}
$$

The instantaneous flux at any axial station is given by

$$
Q(X, t)=\int_{h_{1}(x)}^{h_{2}(x)}(u+1) d y=q+\left(h_{2}-h_{1}\right)
$$

The average flux $\bar{Q}$ along one time period, we have

$$
\bar{Q}=\int_{0}^{1} Q d t=q+1+d
$$


The pressure gradient obtained from equation (18) can be expressed as

$$
\frac{d p}{d x}=\mathrm{M}^{2}\left[\frac{(q+1+d)-1+\varepsilon-\left(h_{2}-h_{1}\right)}{\left[\frac{N_{1}}{\alpha_{1}}\left[\left[\operatorname{Cosh}\left[\alpha_{1} h_{2}\right]-\operatorname{Cosh}\left[\alpha_{1} h_{1}\right]\right]\right]+\left[\frac{N_{2}}{\alpha_{1}}\left[\left[\operatorname{Sinh}\left[\alpha_{1} h_{2}\right]-\operatorname{Sinh}\left[\alpha_{1} h_{1}\right]\right]\right]\right]-\left(h_{2}-h_{1}\right)\right.}\right](17)
$$

The pressure rise (drop) over one cycle of the wave can be obtained as

$$
\begin{gathered}
\Delta_{P}=\int_{0}^{1}\left(\frac{d p}{d x}\right) d x= \\
\int_{0}^{1}\left(\frac{\mathrm{M}^{2}((q+1+d)-1+d)-\left(h_{2}-h_{1}\right)}{\left(\left[\frac{N_{1}}{\alpha_{1}}\left[\left[\operatorname{Cosh}\left[\alpha_{1} h_{2}\right]-\operatorname{Cosh}\left[\alpha_{1} h_{1}\right]\right]\right]-\left[\frac{N_{2}}{\alpha_{1}}\left[\left[\operatorname{Sinh}\left[\alpha_{1} h_{2}\right]-\operatorname{Sinh}\left[\alpha_{1} h_{1}\right]\right]\right]\right]\right)-\left(h_{2}-h_{1}\right)\right.}\right) d x
\end{gathered}
$$

\section{NUMERICAL RESULTS AND DISCUSSION}

In this section is concerned with the discussion of axial velocity and pressure gradient for different quantities. The axial velocity is shown in the figures (1) to (8) for different values of Magnetic field (M) with the phase shipt $\square \square \square \square \square \square \square \square$ and $\square \square \square \square \square / 4$. The axial velocity distribution (u) with Magnetic field (M) as depicted in figures (1) to (4) for the phase shipt $\square \square \square \square \square \square$ with $\phi_{1}=0.7, \phi_{2}=1.2, \mathrm{x}=0.25, \mathrm{~d}=2$. We observed that the axial velocity increaseswith increase in Magnetic field (M) for all the two cases $\frac{d p}{d x}=-0.5, \frac{d p}{d x}=-1$.It is interesting to note that the opposite behaviour observed for $\frac{d p}{d x}=0.5, \frac{d p}{d x}=1$ as shown in Figures (3) and (4).Figure (5) to (8) displays the impact of Magnetic field (M) on an axial velocity for the phase shipt $\square \square \square \square \square / 4$. It is interested to note that the maximum velocity increases with increase in Magnetic field (M) even though for phase shipt $\square \square \square \square \square / 4$ for all the two cases $\frac{d p}{d x}=-0.5, \frac{d p}{d x}$ $=-1$. However, opposite effects are noticed for $\frac{d p}{d x}=0.5, \frac{d p}{d x}=1$ as shown in figures (7) and (8). Figures (9) - (11) illustrate the variations of $\frac{d p}{d x}$ for a given wavelength versus $\mathrm{x}$, where $x \in[0,1]$. Figure (9) illustrates the influence of average volume flow rate $\bar{Q}$ on the pressure gradient $\mathrm{dp} / \mathrm{dx}$.It is interested to notein the wider part of channel $x \in[0,0.2]$ and $x \in[0.7,1]$ the pressure gradient is relatively small. Hence, the flow can easily pass without imposing large pressure gradient. It is further observed that the pressure gradient increases by increasing the values of x.Figure (10) showsthat the influence of Magnetic field (M)on the pressure gradient $\mathrm{dp} / \mathrm{dx}$. This figure shows that the pressure gradient $\mathrm{dp} / \mathrm{dx}$ is rapidly increases with increase in Magnetic field (M) in the entire flow field.Figure (11) showsthat the influence of $\square \square$ on the pressure gradient $\mathrm{dp} / \mathrm{dx}$. We notice that the pressure gradient $\mathrm{dp} / \mathrm{dx}$ is relatively small in the part of the channel $x \in[0.7,1]$.It is further observed that the pressure gradient increases by increasing the values of $\square$. 
International Journal of Recent advances in Mechanical Engineering (IJMECH) Vol.3, No.4, November 2014

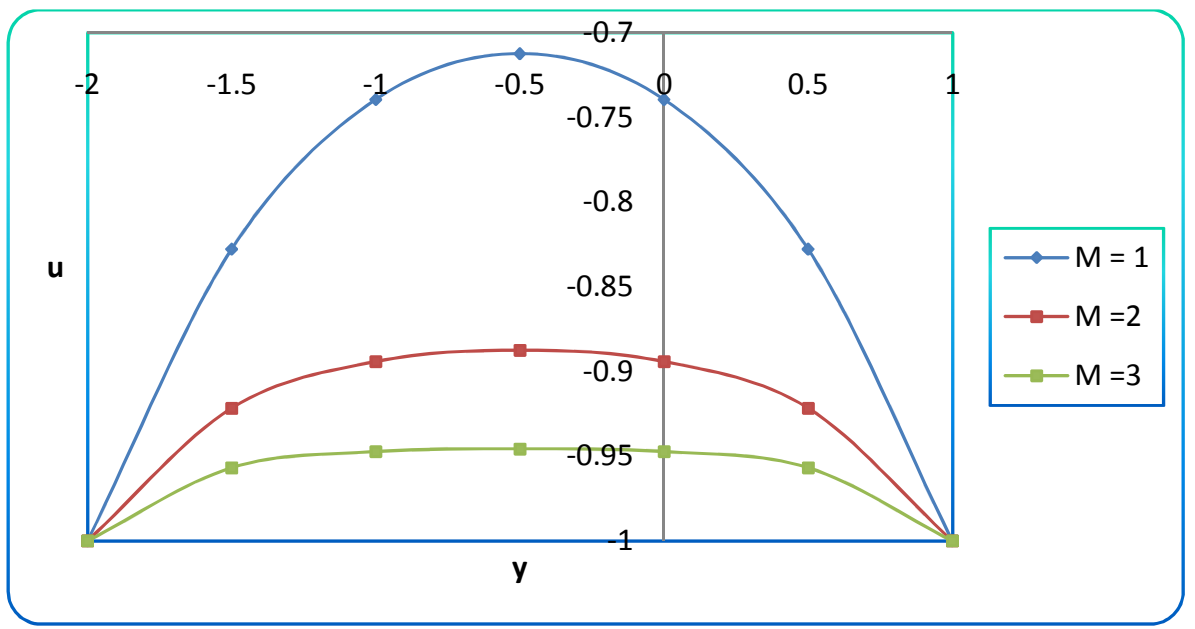

Figure 1.The variation of $\mathrm{u}$ with y for different values of with $\frac{d p}{d x}=-0.5$, $\theta=0, \phi_{1}=0.7, \phi_{2}=1.2, \mathrm{x}=0.25, \mathrm{~d}=2$.

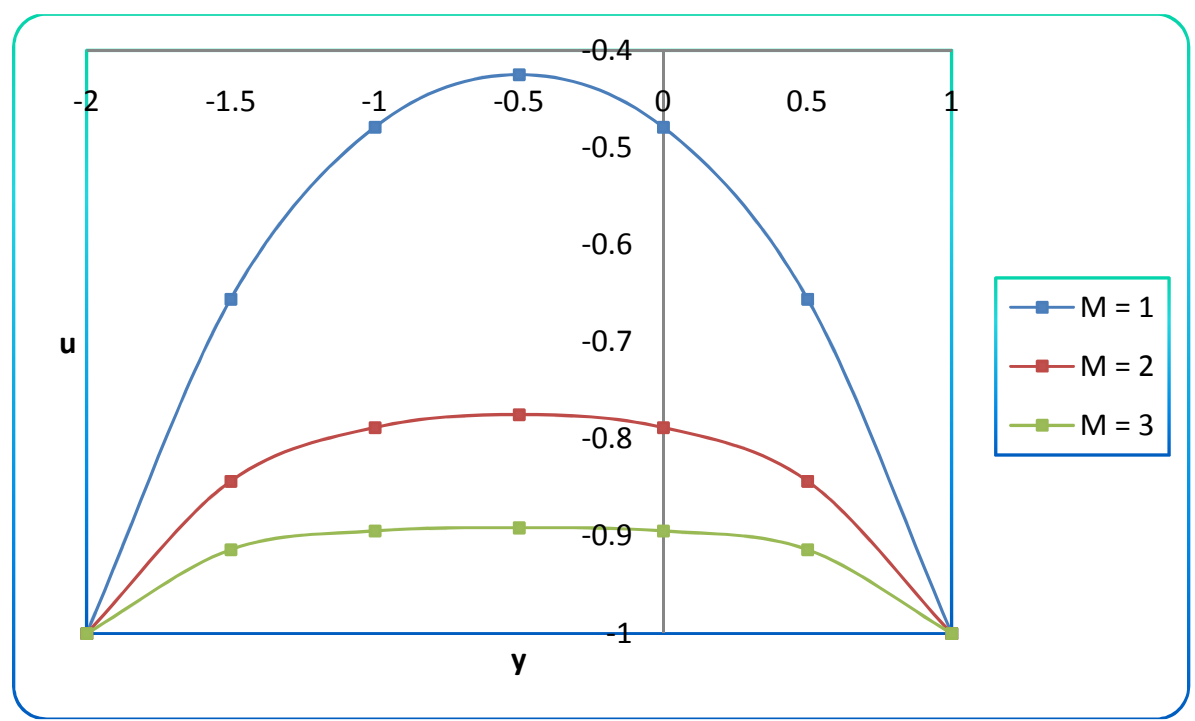

Figure 2.The variation of $\mathrm{u}$ with $\mathrm{y}$ for different values of with $\frac{d p}{d x}=-1$, $\theta=0, \phi_{1}=0.7, \phi_{2}=1.2, \mathrm{x}=0.25, \mathrm{~d}=2$. 
International Journal of Recent advances in Mechanical Engineering (IJMECH) Vol.3, No.4, November 2014

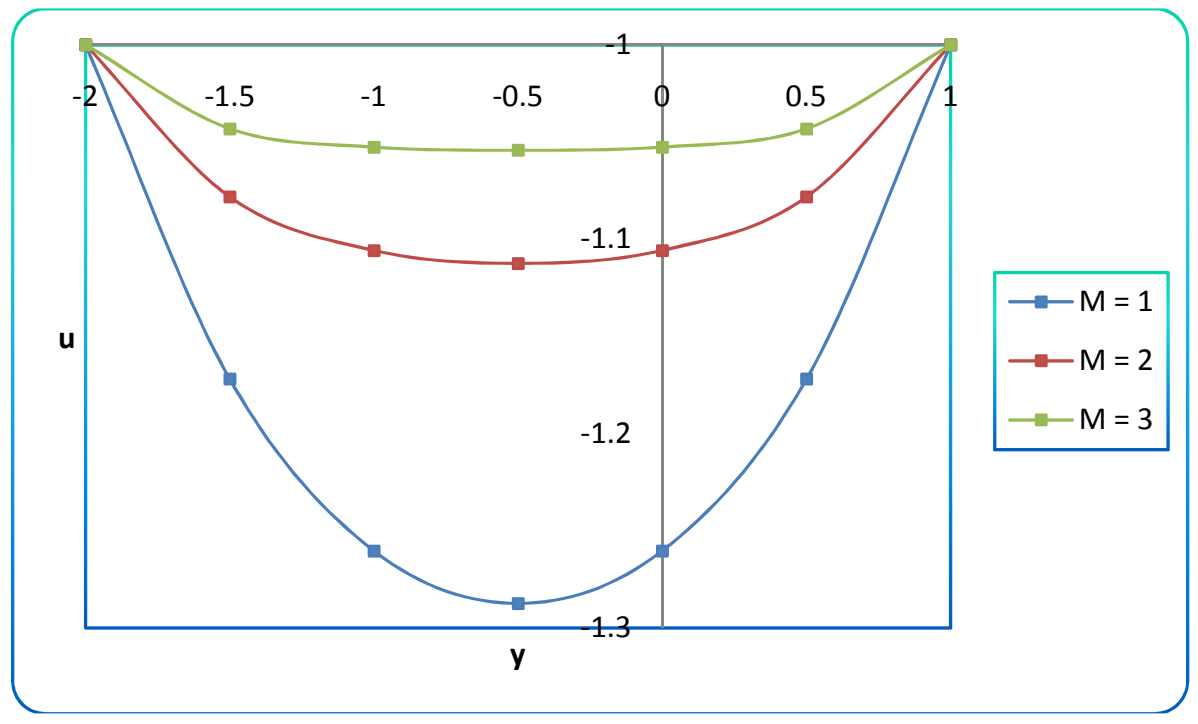

Figure 3.The variation of $\mathrm{u}$ with $\mathrm{y}$ for different values of with $\frac{d p}{d x}=0.5$, $\theta=0, \phi_{1}=0.7, \phi_{2}=1.2, \mathrm{x}=0.25, \mathrm{~d}=2$.

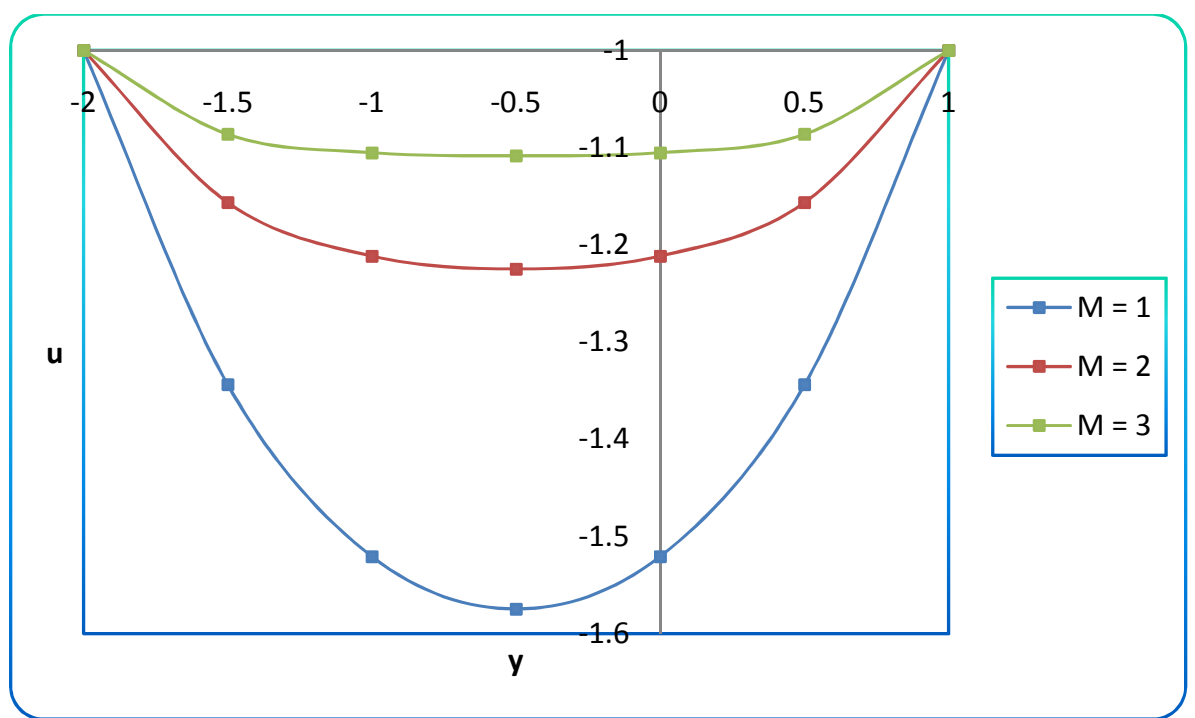

Figure 4.The variation of $\mathrm{u}$ with y for different values of with $\frac{d p}{d x}=1$, $\theta=0, \phi_{1}=0.7, \phi_{2}=1.2, \mathrm{x}=0.25, \mathrm{~d}=2$. 
International Journal of Recent advances in Mechanical Engineering (IJMECH) Vol.3, No.4, November 2014

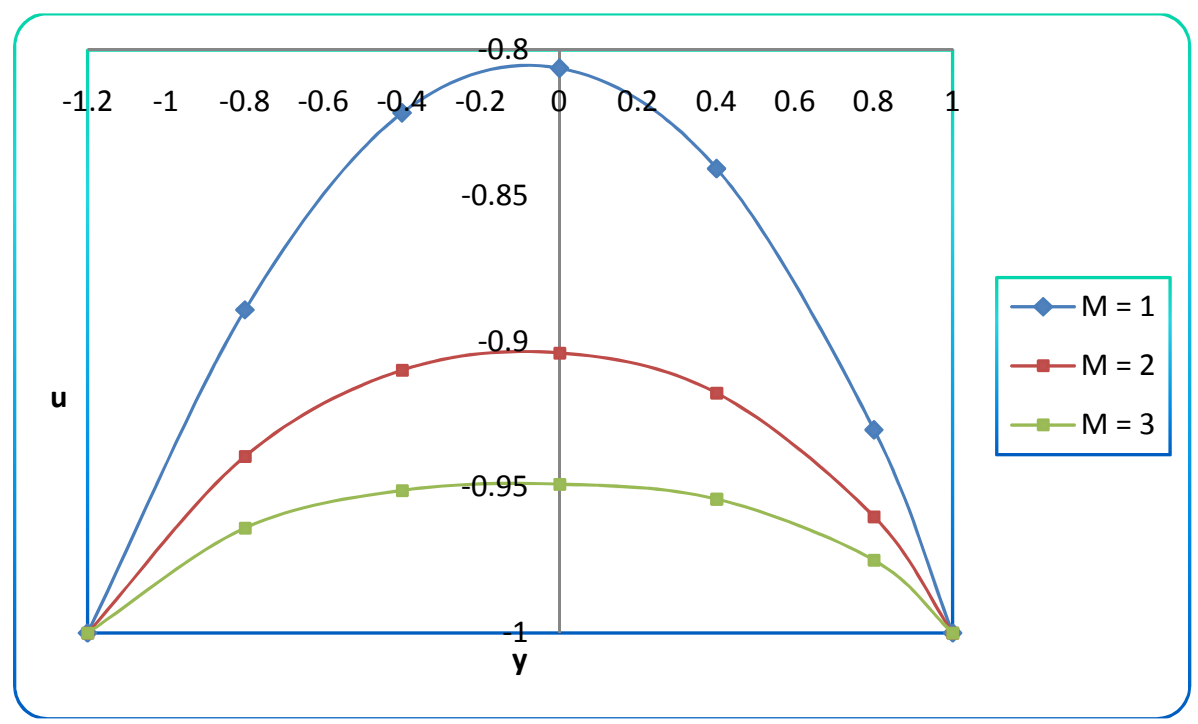

Figure 5. u with y for different values

$\frac{d p}{d x}=-0.5, \phi_{2}=1.2, \mathrm{x}=0.25, \mathrm{~d}=2, \theta=\frac{\pi}{4}, \phi_{1}=0.7$

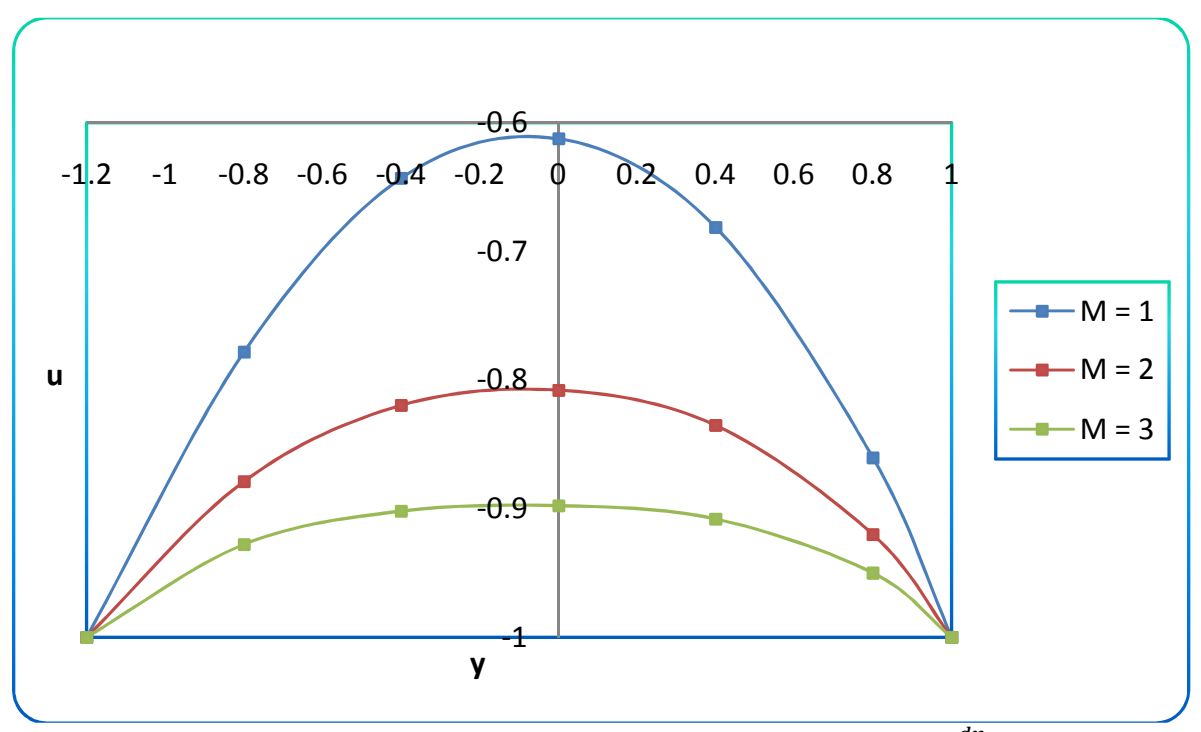

Figure 6.The variation of $\mathrm{u}$ with $\mathrm{y}$ for different values of with $\frac{d p}{d x}=-1$,

$$
\theta=\frac{\pi}{4}, \phi_{1}=0.7, \phi_{2}=1.2, \mathrm{x}=0.25, \mathrm{~d}=2 .
$$


International Journal of Recent advances in Mechanical Engineering (IJMECH) Vol.3, No.4, November 2014

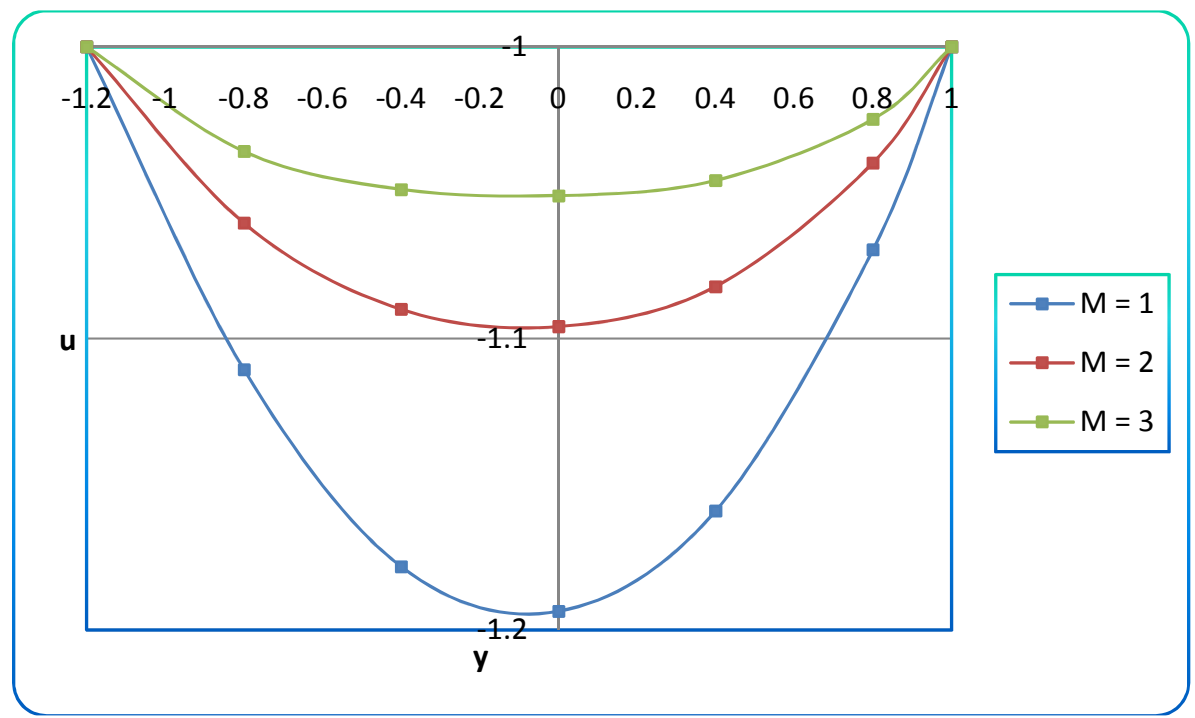

Figure 7.u with y for different values

$\frac{d p}{d x}=0.5, \phi_{1}=0.7, \mathrm{x}=0.25, \phi_{2}=1.2, \theta=\frac{\pi}{4}, \mathrm{~d}=2$.

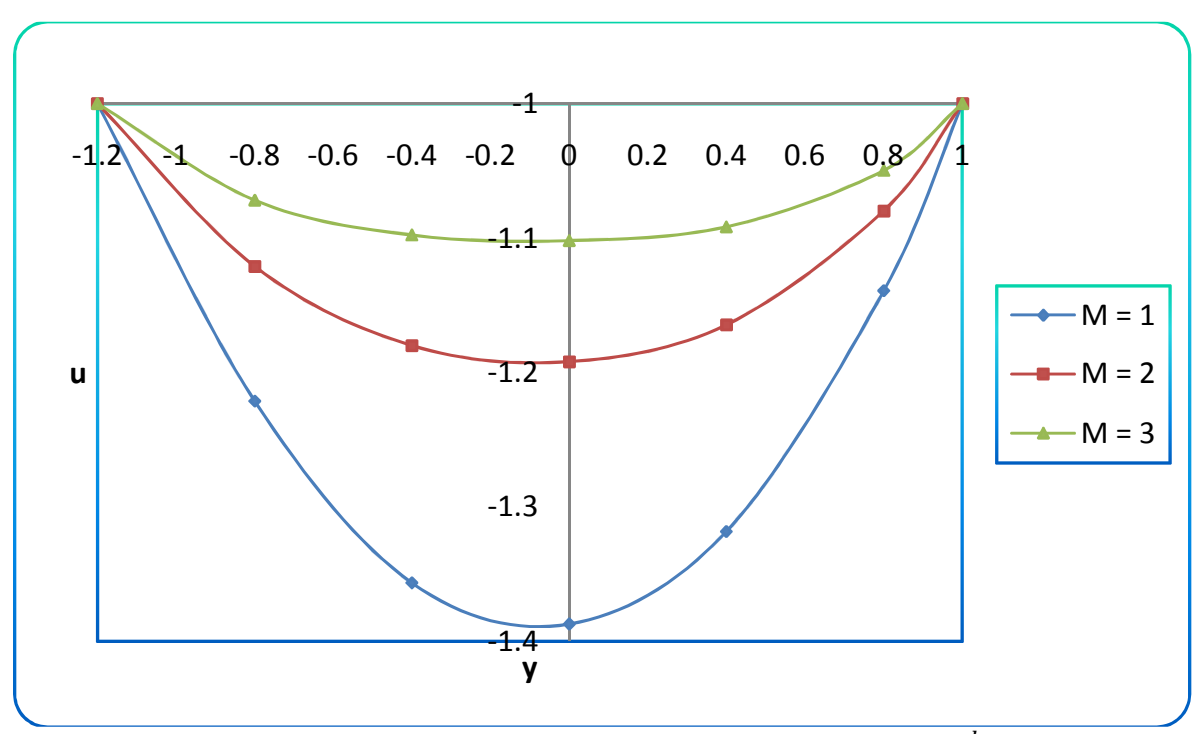

Figure 8.The variation of $\mathrm{u}$ with $\mathrm{y}$ for different values of with $\frac{d p}{d x}=1$,

$$
\theta=\frac{\pi}{4}, \phi_{1}=0.7, \phi_{2}=1.2, \mathrm{x}=0.25, \mathrm{~d}=2 .
$$


International Journal of Recent advances in Mechanical Engineering (IJMECH) Vol.3, No.4, November 2014

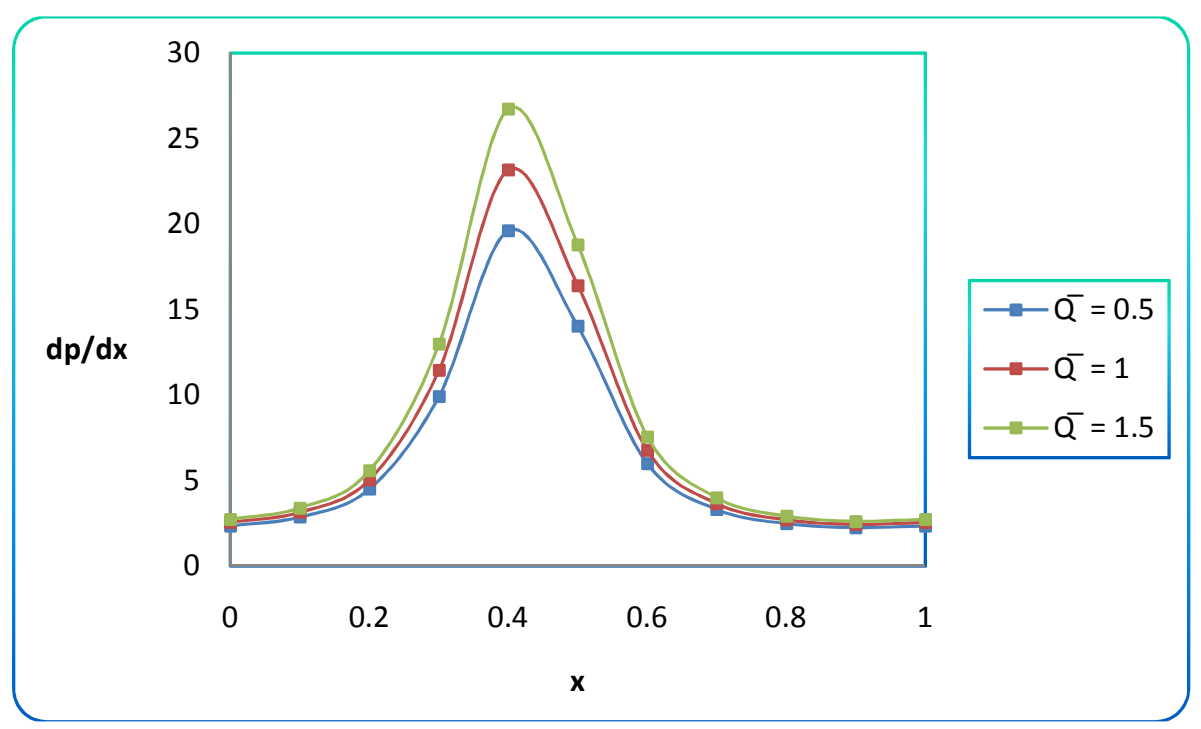

Figure 9.Pressure gradient versus $\mathrm{x}$ for $\theta=\frac{\pi}{4}, \phi_{1}=0.7$

$$
\phi_{2}=1.2, \mathrm{~d}=2, \mathrm{M}=1
$$

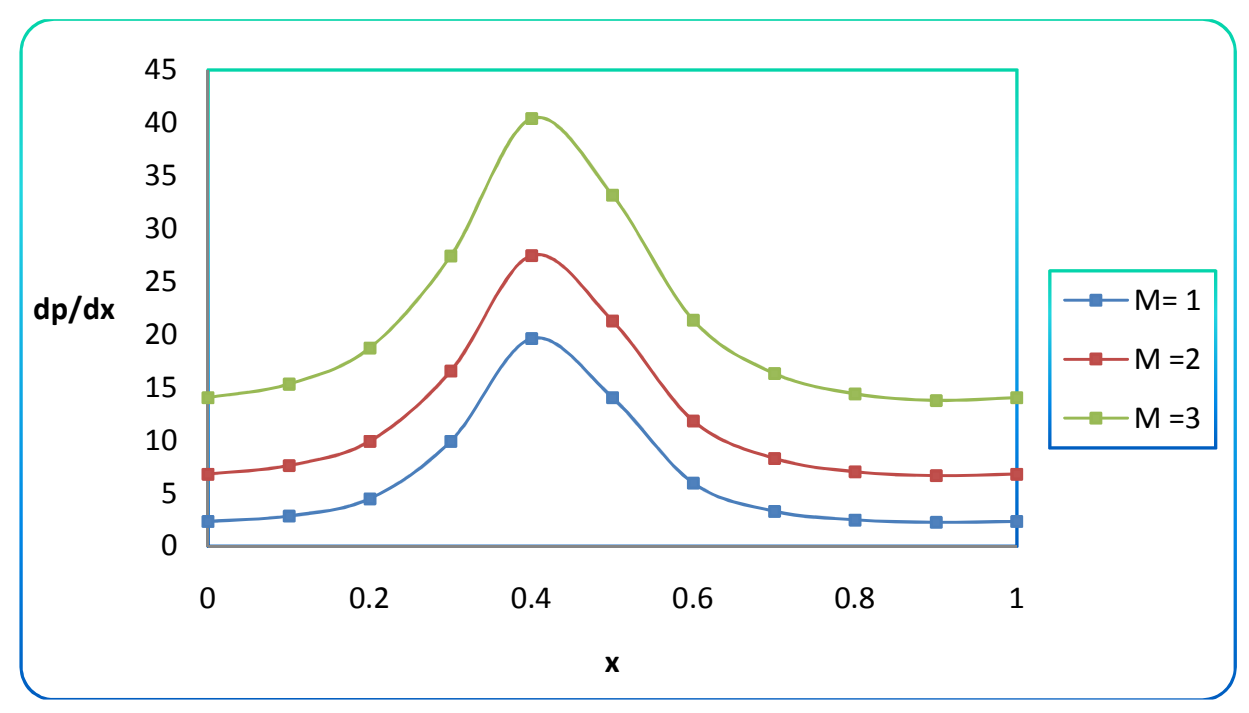

Figure 10.Pressure gradient versus $\mathrm{x}$ for $\theta=\frac{\pi}{4}, \phi_{1}=0.7$,

$$
\phi_{2}=1.2, \mathrm{~d}=2, \bar{Q}=0.5
$$




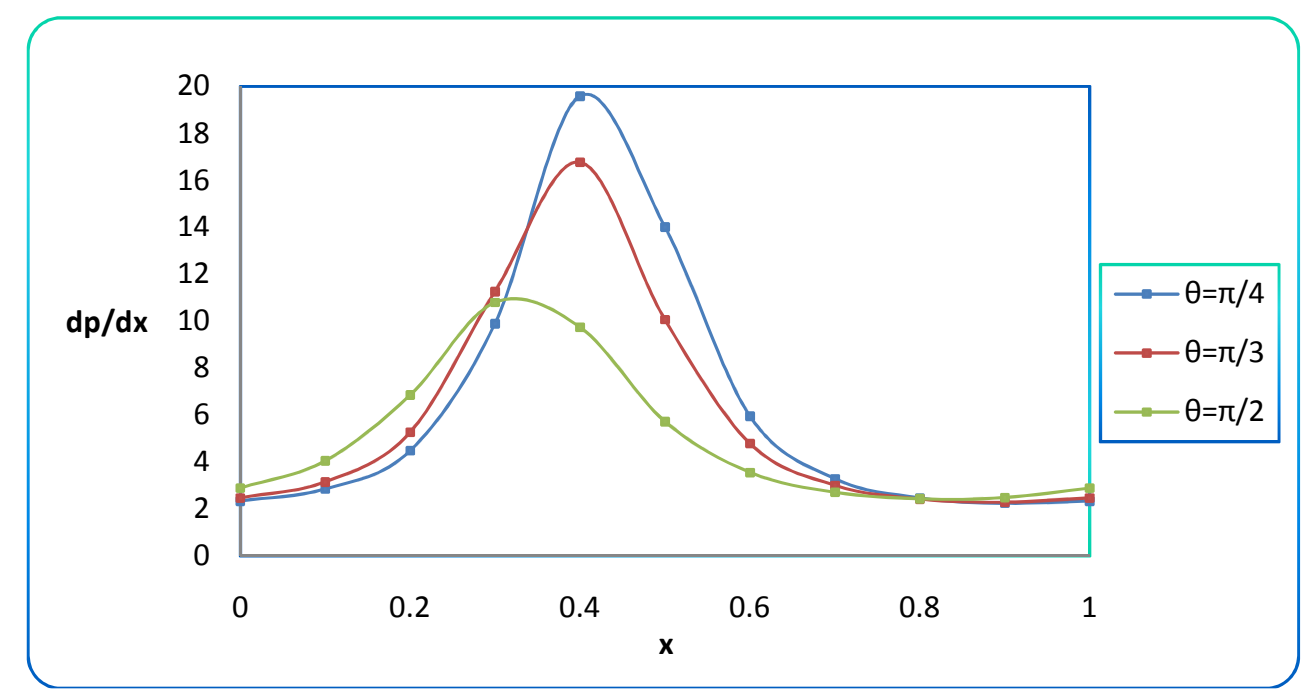

Figure 11.Pressure gradient versus $\mathrm{x}$ for $\phi_{1}=0.7$, $\phi_{2}=1.2, \mathrm{~d}=2, \bar{Q}=0.5, \mathrm{M}=1$

\section{CONCLUSIONS}

Peristaltic flow of blood through coaxial vertical channel with effect of magnetic field: blood flow study has been studied under long wavelength approximation. We conclude the following observations:

1. It is observed that the maximum velocity increases with increase in Magnetic field (M) even though for phase shipt $\square \square \square \square \square / 4$ for all the two cases $\frac{d p}{d x}=-0.5, \frac{d p}{d x}=-$ 1.However, opposite effects are noticed for $\frac{d p}{d x}=0.5, \frac{d p}{d x}=1$

2. It is observed that the wider part of channel $x \in[0,0.2]$ and $x \in[0.7,1]$ the pressure gradient is relatively small. Hence, the flow can easily pass without imposing large pressure gradient.

3. Pressure gradient $\frac{d p}{d x}$ increases in the entire part of the channel $x \in[0,1]$

\section{REFERENCES}

[1] T.W.Lathem, Fluid motion in a peristaltic pump, Master's thesis, MIT, Cambridge, (1966).

[2] Y.C.Fung and C.S.Yih, Peristaltic Transport, Journal of AppliedMechanics, 35 (1968), 669-675.

[3] A.H.Shapiro, M.Y. Jaffrin andS.L.Weinberg, Peristaltic pumping with long wavelength at low Reynolds number,Journal of Fluid Mechanics., 37(1969), 799-825.

[4] T.D.Brown and T.K.Hung, Computational and Experimental Investigations of Two-Dimensional Non-Linear Peristaltic Flows, Journal of Fluid Mechanics, 83 (1977), 249-273.

[5] S.Takabatakeand K. Ayukawa, Numerical Study of Two Dimensional Peristaltic Flows, Journal of FluidMechanics, 122 (1982), 439-465.

[6] S.Takabatakeand K. Ayukawa, Peristaltic Pumping in Circular Cylindrical Tubes: A Numerical Study ofFluid Transport and its Efficiency, Journal of Fluid Mechanics, 193 (1988), 267-283.

[7] L.M.Srivastava, Peristaltic Transport of a Couple Stress Fluid, RheologicaActa, 25(1986), 638-641.

[8] L.M.SrivastavaandV.P. Srivastava, Peristaltic Transport of Blood: Casson Model-II, Journal of Biomechanics, 17 (1984), 821-829. 
[9] L.M.Srivastava andV.P. Srivastava,Peristaltic Transport of a Power-Law Fluid: Application to the ductusEfferentes of the Reproductive Tract, RheologicaActa, 27 (1988), 428-433.

[10] L.M.Srivastava, V.P. Srivastavaand S.N.Sinha, Peristaltic Transport of a Physiological Fluid: Flow in Non-Uniform Geometry, Biorheology, 20 (1983), 153-166.

[11] A.M. Siddiqui and W.H.Schwarz, Peristaltic Flow of a Second Order Fluid in Tubes, Journal of NonNewtonian Fluid Mechanics, 35 (1994), 257-284.

[12] R.A.Ramachandra and S.Usha, Peristaltic Transport of Two Immiscible Viscous Fluids in a Circular Tube, Journal of Fluid Mechanics, 298 (1995), 271-285.

[13] E.F.Elshehawey and A.M. Sobh, Peristaltic Viscoelastic Fluid Motion in a Tube, International Journal of Mathematics and Mathematical Sciences, 26 (2001), 21-34.

[14] E.F.Elshehawey , A.M. Sobhand E.M. Elbarbary, Peristaltic Motion of a Generalized Newtonian Fluid through a Porous Medium, Journal of Physical Society of Japan, 69 (2000), 401-407.

[15] S.Ravikumar, G.PrabhakaraRao and R. Siva Prasad, Peristaltic flow of a couple stress fluid flows in a flexible channel under an oscillatory flux,International journal of Applied Mathematics and Mechanics,6 (13) (2010), 58-71.

[16] S.Ravikumarand R.Siva Prasad, Interaction of pulsatile flow on the peristaltic motion of couple stress fluid through porous medium in a flexible channel, EuropeanJournal of Pureand Applied Mathematics.3(2010), 213-226.

[17] S.Ravikumar ,Peristaltic Fluid Flow Through Magnetic Field At Low Reynolds Number In A Flexible Channel Under An Oscilatory Flux,International journal of Mathematical Archive,4(1) (2013),36-52.

[18] S.Ravikumar, G.PrabhakaraRao and R. Siva Prasad,Peristaltic flow of a second order fluid in a flexible channel,International journal of Applied Mathematics and Mechanics,6 (18)(2010), 13-32.

[19] S.Ravikumar, Peristaltic transportation with effect of magnetic field in a flexible channel under an oscillatory flux,Journal of Global Research in Mathematical Archives 1(5) (2013), 53-62.

[20] S. Ravikumar, Hydromagnetic Peristaltic Flow of Blood with Effect of PorousMediumthrough coaxial vertical Channel: A Theoretical Study, International Journal of Engineering Sciences \& ResearchTechnology, 2(10) (2013),2863-2871.

[21] S.Ravikumar, G.PrabhakaraRao and R. Siva Prasad, Hydromagnetic two-phase viscous ideal fluid flow in a parallel plate channel under a Pulsatile pressure gradient,International Journal of Fluid mechanics Research, 39(4) (2012), 291-300, 2012.

[22] S.Ravikumar,N.AmeerAhamad, Peristaltic Motion with Porous Medium through CoaxialVertical Channel: ATheoretical Study, International Journal of Engineering Sciences \& ResearchTechnology, 3(1) (2014),314-323.

[23] K.Vajravelu and S. Sreenadh, Peristaltic transport of a Herschel-Bulkley fluid in an inclined tube,International journal of Non-LinearMechanics, 40 (2005), 83.

[24] S.Nadeem andN.S.Akbar, Effects of heat transfer on the peristaltic transport ofMHD Newtonian fluid withvariable viscosity:Application of Adomian decomposition method,Communications in Nonlinear Science and Numerical Simulation, 14 (2009), 3844-3855.

[25] S.Nadeem and S. Akram, Heat transfer in a peristaltic flow of MHD fluid with partial slip,Communications in Nonlinear Science and Numerical Simulation, 15 (2010), 312-321.

[26] N.Ali, T. Hayat and M. Sajid, Peristaltic flow of a couple stress fluid in an asymmetric channel,Biorheology, 44 (2007), 125-138.

[27] M.H. Haroun, Non-linear peristaltic flow of a fourth grade fluid in an inclined asymmetric channel, Comput. Mater.Sci., 39 (2007), 324-333.

[28] A.El Hakeem, A. El Naby andA.E.ElMisiery, Efects of an endoscope and generalized Newtonian fluid onperistaltic motion, Applied Mathematics and Computation, 128 (2002), 19-35.

[29]M.H.Haroun, Effects of Deborah number and phase difference on peristaltic transport of a third order fluidin an asymmetric channel,Communications in Nonlinear Science and Numerical Simulation, 12 (2007), 1464-1480.

[30] T.Hayat,N.Ali and S. Asghar, Hall effects on peristaltic flow of a Maxwell fluid in a porous medium,Phys.Lett. A 363 (2007), 397-403.

[31] Kh.S.Mekheimer, Nonlinear peristaltic transport through a porous medium in an inclined planar channel, Journal of Porous Media, 6 (2003), 189-201.

[32] E.F.Elshehawey, N.T.Eldabe, E.M. Elghazy and A.Ebaid, Peristaltic transport in an asymmetric channelthrough porousmedium,Applied Mathematics and Computation, 182(2006), 140-150.

[33] A. El Hakeem, A. El Naby, A.E. El Misiery, Hydromagnetic flow of generalized Newtonian fluid through a uniform tube through peristalsis,Applied Mathematics and Computation, 173 92006), 856871. 
[34] T.Hayat and N. Ali, A mathematical description of peristaltic hydromagnetic flow in a tube. Applied Mathematics and Computation, 188 (2007), 1491- 1502.

[35] Abd El Hakeem,Abd El Naby, A.E.M. El Misery and M.F. Abd El Kareem, Effects of a magnetic field on trapping through peristaltic motion for generalize Newtonian fluid in a channel, Physica A ,367 (2006), 79.

[36] V.P. Srivastava and M. Saxena, A two-fluid modal of non-Newtonian blood flow induced by peristaltic waves, RheologicaActa, 34 (1995), 406.

[37] T. Hayat, Masood Khan, A.M. Siddiqui, K. Hutter and S. Asghar, Non-liner peristaltic flow of a nonNewtonian fluid under effect of a magnetic field in a planner channel, Communications in Nonlinear Science and Numerical Simulation, 12 (2007), 910.

[38] H.L. Agarwal and B. Anwaruddin, Peristaltic flow of blood in a branch, Ranchi Univ. Math. J, 15 (1984), 111-121.

[39] A. Li, N.I. Nesterov, S.N. Malikovaand V.A. Kiiatkin, The use of an impulsive magnetic field in the combined therapy of patients with stone fragments in the upper urinary tract, Vopr. KurortolFizioter Lech FizKult, 3 (1994), 22-24.

[40] AmitMedhavi, Peristaltic Pumping of a Non-Newtonian Fluid,AAM: International Journal, Vol. 3, No. 1 (2008), 137-148.

[41] AmitMedhavi and U.K. Singh, Peristaltic Induced Flow of a Particulate Suspension in a Non-Uniform Geometry,AAM: International Journal, Vol. 6, Issue 1[Previously, Vol. 6, Issue 11, pp. 2064 - 2077] (2011), $323-336$.

\section{Author}

Dr.S.RaviKumar has done B.Sc. (Mathematics) from Sri Krishna Devaraya University, Anantapur, India in 1999, M.Sc (Mathematics) from SriVenkateswara University, Tirupati, India in 2002,M.Phil(Fluid Mechanics)from Sri Krishna Devaraya University, Anantapur, India in 2006 and Ph.D (Fluid Mechanics) from Sri Krishna Devaraya University, Anantapur, India in 2009. He has published more than 20 papers in International / National Journals. His research areas of interest are Peristaltic fluid flows, Couple stress fluid flows, Heat and Mass Transfer,MHD fluid flows and Fluid Dynamics.

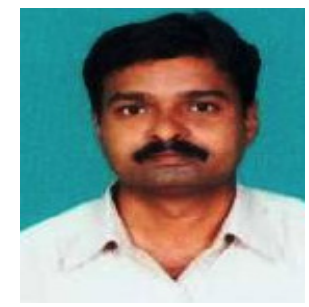

